Daniel Ramos Louzada

Detecção e caracterização de danos estruturais através de sensores a rede de Bragg e Redes Neurais Artificiais

Tese apresentada como requisito parcial para obtenção do título de Doutor pelo Programa de Pós-Graduação em Engenharia Mecânica da PUC-Rio.

Orientador: Prof. Arthur Martins Barbosa Braga

Co-orientador: Prof. Carlos Roberto Hall Barbosa 
Daniel Ramos Louzada

\section{Detecção e caracterização de danos estruturais através de sensores a rede de Bragg e Redes Neurais Artificiais.}

Tese apresentada como requisito parcial para obtenção do título de Doutor pelo Programa de Pós-Graduação em Engenharia Mecânica da PUC-Rio. Aprovada pela Comissão Examinadora abaixo assinada.

Prof. Arthur Martins Barbosa Braga Orientador

Departamento de Engenharia Mecânica - PUC-Rio

Prof. Carlos Roberto Hall Barbosa

Co-orientador

Programa de Pós-Graduação em Metrologia - PUC-Rio

José Luiz de França Freire Departamento de Engenharia Mecânica - PUC-Rio

Prof. Luis Carlos Guedes Valente Departamento de Engenharia Mecânica - PUC-Rio

Prof. Marcelo Amorim Savi, UFRJ Universidade Federal do Rio de Janeiro

Prof. Lazaro Valentim Donadon Universidade Federal de Minas Gerais

Prof. José Eugenio Leal Coordenador Setorial do Centro

Técnico Científico - PUC-Rio

Rio de Janeiro, 22 de outubro de 2013 
Todos os direitos reservados. É proibida a reprodução total ou parcial do trabalho sem autorização da universidade, do autor e do orientador.

\section{Daniel Ramos Louzada}

Graduou-se em Licenciatura Plena Física, em janeiro de 2003, pela Universidade do Estado do Rio de Janeiro UERJ. Recebeu o título de Mestre pela Pontifícia Universidade Católica do Rio de Janeiro em 2006.

Ficha Catalográfica

Louzada, Daniel Ramos

Detecção e caracterização de danos estruturais através de sensores a rede de Bragg e Redes Neurais Artificiais/ Daniel Ramos Louzada; orientador: Arthur Martins Barbosa Braga; Co-orientador: Carlos Roberto Hall Barbosa. - Rio de Janeiro: PUC-Rio, Departamento de Engenharia Mecânica, 2013.

v., 173 f.: il. (color.); $30 \mathrm{~cm}$

Tese (doutorado) - Pontifícia Universidade Católica do Rio de Janeiro, Departamento de Engenharia Mecânica, 2013.

Incluí bibliografia.

1. Engenharia Mecânica - Teses. 2. Detecção de defeitos por corrosão em materiais tipo placa. 3.Integridade Estrutural. 4 Elementos Finitos. 5. Extensiometria. 6.Teste em zona elástica. I Braga, Arthur Martins Barbosa.II Barbosa, Carlos Roberto Hall III. Pontifícia Universidade Católica do Rio de Janeiro. Departamento de Engenharia Mecânica. IV. Título. 
Dedico todo este trabalho ao meu querido pai, Ruy Carlos e a minha saudosa mãe, Maria Hermínea que sempre preencheram todos os dias da minha vida. 


\section{Agradecimentos}

Aos meus pais que sempre me apoiaram nas minhas decisões.

A toda a minha família que sempre esteve presente nos meus momentos mais difíceis.

Aos meus orientadores Arthur Martins Barbosa Braga e Carlos Roberto Hall Barbosa, pelo constante apoio e incentivo.

À Paula Medeiros Proença de Gouvêa e Luis Carlos Guedes Valente por todo apoio e orientações durante o andamento do projeto da qual esta tese resultou.

À todos os funcionários do departamento de engenharia mecânica da PUC que sempre me auxiliaram em tudo o que precisei.

Aos meus amigos da pós graduação do DEM, que sempre estiveram ao meu lado, me ajudando sempre que possível.

À FINEP e a PUC-Rio por todo apoio recebido. 


\section{Resumo}

Ramos, Daniel Louzada; Braga, Arthur Martins Barbosa; Barbosa, Carlos Roberto Hall . Detecção e caracterização de danos estruturais através de sensores a rede de Bragg e Redes Neurais Artificiais. Rio de Janeiro, 2013. 173 p. Tese de Doutorado - Departamento de Engenharia Mecânica, Pontifícia Universidade Católica do Rio de Janeiro.

O aumento dos custos relacionados aos processos de manutenção em estruturas como aeronaves, aliadas à crescente demanda das mesmas, alimentam a necessidade de investimentos em técnicas inovadoras de monitoramento estrutural. Dessa forma, o trabalho realizado nesta tese, busca o desenvolvimento de uma técnica de monitoramento ativo, visando o acompanhamento de parâmetros da estrutura analisada, a fim de identificar e caracterizar processos de dano não visíveis, tais como corrosão e delaminação. A metodologia empregada, teve como base a análise dos padrões de deformação superficial, obtidos com o uso de grades de sensores à fibra óptica baseadas em redes de Bragg (FBG). Inicialmente, tais padrões foram provocados por carregamentos estáticos (tração), e posteriormente por atuadores PTZ fixados à estrutura. Estes últimos são submetidos a uma voltagem alternada e frequência fixa. Esta técnica apresenta todas as vantagens dos sensores FBG (massa e dimensões reduzidas, imunidade eletromagnética, elevado poder de multiplexação e alta sensibilidade entre outras), alem de permitir a visualização de alterações nos padrões de deformação, provocados por danos, através da variação da frequência de excitação. Com relação à interpretação dos resultados, a estratégia empregada consistiu em separar o problema de detecção e caracterização dos danos. Dessa forma, a detecção é realizada comparando a energia das deformações superficiais dos corpos de prova nos casos com e sem defeito, enquanto a caracterização é obtida através a utilização de redes neurais artificiais (RNA), por meio de rotinas de reconhecimento de padrões.

\section{Palavras-Chave}

Monitoramento da Saúde Estrutural (SHM); Sensores de Rede de Bragg (FBG); Delaminação em Compósitos; Corrosão; Redes Neurais Artificiais. 


\begin{abstract}
Ramos, Daniel Louzada; Braga, Arthur Martins Barbosa; Barbosa, Carlos Roberto Hall (Advisor). Detection and characterization of structural damage using fiber Bragg grating sensors and artificial neural networks. Rio de Janeiro, 2013. 173 p. Tese de Doutorado - Departamento de Engenharia Mecânica, Pontifícia Universidade Católica do Rio de Janeiro.
\end{abstract}

The higher costs related to maintenance processes in structures such as aircraft, coupled with the growing demand of them, fueling the need for investment in innovative techniques for structural monitoring. Thus, the work done in this thesis seeks to develop a technique of active monitoring, aiming at monitoring of structure parameters analyzed in order to identify and characterize processes of hidden damage such as corrosion and delamination. The maid methodology was based on the analysis of patterns of surface deformation, obtained with the use of nets of optical fiber sensors based on fiber Bragg gratings ( FBG ). Initially, these patterns were caused by static loads (tension), and later by PTZ actuators fixed to the frame, who are subjected to an $\mathrm{AC}$ voltage and fixed frequency. This technique has all the advantages of the FBG's sensors (mass and small dimensions, electromagnetic immunity, high multiplexing's power and high sensitivity among others), in addition to allowing visualization of changes in the patterns of deformation caused by damage, by varying the frequency excitation. With respect to the interpretation of the results, the strategy employed was to separate the problem of detection and characterization of damage. Thus, the detection is performed by comparing the deformation energy of the surface of the specimens in the cases with and without defect, whereas the characterization is obtained through the use of artificial neural networks (ANN) by means of pattern recognition routines.

\title{
Keywords
}

Structural Health Monitoring (SHM); Fiber Bragg Grating Sensors; Artificial Neural Networks; Corrosion; Composite Delamination. 


\section{Sumário}

1 Introdução 22

1.1 Contextualização e motivação 22

1.2 Objetivos da tese $\quad 24$

1.3 Estrutura da Tese 25

2 Sensores a fibra óptica $\quad 27$

2.1 Fundamentos 27

2.2 Classificação dos Sensores a Fibra Óptica 33

2.2.1 Local de Interrogação 33

2.2.2 Configuração de Sensoriamento 34

2.2.3 Interrogação do Sinal 36

$\begin{array}{lll}2.2 .4 & \text { Técnicas de endereçamento } & 38\end{array}$

2.3 Sensores de Redes de Bragg (FBG) 39

2.3.1 Caracterização Histórica 40

2.3.2 Princípios Básicos de Sensores FBGs 41

2.3.3 Descrição Matemática $\Delta \lambda \boldsymbol{B}$ com a temperatura e tração. 43

2.3.4 Sensibilidade 45

2.3.5 Gravação de Redes de Bragg em fibras ópticas 46

2.3.6 Técnicas de Leitura dos sensores FBG 49

3 Sistema de Monitoramento Estrutural - SHM 51

$\begin{array}{lll}3.1 & \text { Introdução } & 51\end{array}$

3.2 Implementação de um Sistema SHM 52

3.3 Formas de interrogação estrutural 54

3.3.1 Sensores e Atuadores 55

3.4 Transmissão de Dados 56

3.5 Sistemas SHM Propostos $\quad 57$

3.5.1 Estruturas de Alumínio e Corrosão 57

3.5.2 Laminados Compósitos e Delaminação 61

3.6 Processamento de sinais 64 
4 Redes Neurais Artificiais - RNAs 66

4.1 Histórico 66

4.2 Neurônio Artificial 69

4.3 Funções de Ativação 70

4.4 Arquitetura 71

4.5 Formas de Aprendizado - Treinamento. 73

4.6 Modelagem de uma RNA $\quad 75$

4.6.1 Validação cruzada e generalização e testes do modelo 75

4.6.2 Tratamento dos padrões de entrada para as RNA 76

4.6.3 Número de neurônios 77

5 Monitoramento Estático de Estruturas de Alumínio 79

5.1 Descrição 79

5.2 Simulações Computacionais (Modelagem em ANSYS) 79

5.2.1 Modelagem 80

5.2.2 Mapas de Deformação 82

5.3 Ensaios Experimentais $\quad 87$

5.3.1 Incerteza de Medição 90

5.3.2 Correlação dos Resultados Numéricos e Experimentais 96

5.4 Sistema SHM para corrosão 97

5.4.1 Detecção da corrosão 99

5.4.2 Caracterização da corrosão por RNA 102

5.4.3 Probabilidade de detecção (Probability of Detection - PoD) 105

6 Monitoramento Dinâmico de Compósitos 110

6.1 Simulações Computacionais 110

6.1.1 Modelagem do Problema $\quad 110$

6.1.2 Exame de Frequência 113

6.1.3 Mapas de Deformação 118

6.1.4 Relação entre Malha e Detecção 136

6.2 Ensaios Experimentais 148

6.2.1 Descrição experimental. 148

6.2.2 Ensaios realizados. 150 
6.3 Sistema SHM para Delaminação

6.3.1 Detecção

6.3.2 Probabilidade de Detecção - PoD

7 Conclusão e Discussões 165

7.1 Trabalhos Futuros 168

8 Referencias Bibliográficas 


\section{Lista de figuras}

Figura 1 - Distribuição populacional entre 1950 e 2010.

(Fonte: UN, Population Division, 2011) 22

Figura 2 - Cenário de necessidades a respeito do monitoramento estrutural. 24

$\begin{array}{ll}\text { Figura } 3 \text { - Ilustração de uma fibra óptica. } & 28\end{array}$

Figura 4 - Diferentes padrões de índices de refração em FO. 29

Figura 5 - Fenômeno da reflexão interna total da luz 30

Figura 6 - Trajeto percorrido por um raio de luz em uma fibra óptica. 30

Figura 7- Atenuação óptica causada por curvatura na fibra. 32

Figura 8- Esquema de sensoriamento de um sensor extrínseco. 34

Figura 9- Esquema de sensoriamento de um sensor intrínseco. 34

Figura 10- Representação de um sensor multiponto em uma

mesma fibra óptica (multiplexação).

Figura 11 - Esquema de um circuito óptico de inferênci

a com sensores de modulação de intensidade.

Figura 12 - Esquema de um circuito óptico de inferência

com sensores de modulação de fase.

Figura 13 - Esquema de um circuito óptico de inferência com sensores de modulação de frequência. 38

Figura 14 - Esquemático de uma rede de Bragg impressa em uma fibra. 42

Figura 15 - Esquemático de uma rede de Bragg impressa em uma fibra. 43

Figura 16 - Padrões de modulação existentes em sensores FGB.

a) padrão homogêneo, b) apodization c) Chirp.

Figura 17 - Configuração típica de um sistema de leitura por demodulação por comprimento de onda.

Figura 18 - Configuração típica de um sistema de leitura por demodulação por filtro fixo.

Figura 19 - Diagrama de processos inerentes ao SHM.

Figura 20 - Ilustração do efeito Piezelétrico direto.

Figura 21 - Exemplo da formação de corrosão galvânica em uma 
estrutura de alumínio e aço.

(Fonte: http://aluminumsurface.blogspot.com.br/2009/04/

corrosion-between-anodized-aluminum-and.html, acessado em 15/09/2013). 58

Figura 22 - Corrosão por pontos em uma peça de alumínio

(Fonte: http://www.amteccorrosion.co.uk/aluminium.html, acessado em 15/09/2013).

Figura 23 - Em $a$, é exemplificado a corrosão intergranular em uma

placa de liga de Al, enquanto que em $b$ é observada microscopicamente

a estrutura. (Fonte: http://moraisvinna.blogspot.com.br/2011/10/

quanto-tempo-dura-um-aviao-comercial.html, acessado em 15/09/2013)

60

Figura 24 - Corrosão por esfoliação em uma peça feita de liga de

alumínio. (Fonte: http://www.epoxipiso.com.br/2012/11/

formas-de-corrosao.html, acessado em 15/09/20013)

Figura 25 - Falha estrutural ocorrida em uma aeronave, devido

a falhas na detecção de processos de corrosão por tensão

na sua fuselagem de alumínio.

(Fonte: http://aviationtroubleshooting.blogspot.com.br/2010_10_01_archive 61

Figura 26 - Diagrama de classificação dos materiais compósitos.

Figura 27 - Desenho exemplificando uma seção transversal de um

corpo de material compósito com a presença de delaminação

localizado entre as suas camadas centrais.

Figura 28 - Delaminação observada em um material

compósito hibrido de fibra/epóxi/alumínio, provocada

por uma força de compressão.

Figura 29 - Esquemático de direção de propagação

de sinais durante o processamento de informações pelo

cérebro (Rede Neural natural).

Figura 30 - Ilustração da organização existente entre os neurônios naturais. $\quad 68$

Figura 31 - Representação de um neurônio artificial. $\quad 70$

Figura 32 - Formato das principais funções de ativação. 71

Figura 33 - Representação gráfica de uma topologia de rede neural. 72

Figura 34 - Na figura $a$ ) esta representado uma RNA com uma

camada (Perceptron) enquanto na figura b) a RNA possui 
múltiplas camadas (MLP).

Figura 35 - Rede parcialmente recorrente (Rede de Elman). 73

Figura 36 - Rede totalmente recorrente (Rede de Hopfield). 73

Figura 37 - Relação entre o erro de treinamento e o erro de

validação em uma RNA do tipo MLP com treinamento por Backpropagation. 76

Figura 38 - Condição de carregamento aplicado ao modelo numérico. 81

Figura 39 - Formato das áreas de desgaste provocadas para a

simulação de processos de corrosão.

Figura 40 - Indicação da superfície sobre a qual são coletados

os dados simulados.

Figura 41 - Mapa de deformação superficial $[\mu \varepsilon]$ de uma placa

submetida a uma tração de $1600 \mathrm{~kg}$.

Figura 42 - Mapas de deformação superficial $[\mu \varepsilon]$ de placas

submetidas a uma tração de 1200 kgf e com processos de

corrosão central, com comprometimento de $45 \%$ da espessura inicial.

Figura 43 - Mapas de deformação superficial $[\mu \varepsilon]$ de placas

submetidas a uma tração de $1600 \mathrm{kgf}$ e com processos de

corrosão central, com comprometimento de $45 \%$ da espessura inicial.

Figura 44 - Procedimentos de realizados sobre os dados simulados

a fim de promover a sua redução e adequação à situações experimentais. $\quad 85$

Figura 45 - Filtragem dos mapas de deformação para linhas. 85

Figura 46 - Espaçamento dos sensores ao longo de cada linha de deformação. 86

Figura 47 - Processo de redução e condicionamento dos dados brutos.

Figura 48 - Placa de alumínio (dimensões de 400mm de comprimento,

$130 \mathrm{~mm}$ de largura e $3 \mathrm{~mm}$ de espessura) usinada com um desgaste

no seu centro simulando a presença de uma corrosão.

Figura 49 - Desenho esquemático do posicionamento dos sensores

FBG sobre a placa de alumínio a ser ensaiada.

Figura 50 - a) placa de alumínio com os sensores FBG. B) aparelho

de medição ótica (BraggMETER) e máquina de tração. C) detalhe da placa

de alumínio sendo tracionada.

Figura 51 - Primeiro ensaio de tração com a placa de alumínio com

um desgaste central de $45 \%$ da espessura e área quadrada de lados com $32 \mathrm{~mm} .89$ 
Figura 52 - Resposta de um único sensor durante o ensaio de tração.

Figura 53 - Segundo ensaio de tração com a placa de alumínio com um desgaste central de $45 \%$ da espessura e área quadrada de lados com $32 \mathrm{~mm} .90$

Figura 54 - Principais modelos de distribuição de probabilidade.

Figura 55 - Representação da distribuição dos resultados observados pelo sensor A4, durante o primeiro ensaio de tração.

Figura 56 - Representação da distribuição dos resultados observados

pelo sensor A4, durante o segundo ensaio de tração.

Figura 57 - Comparação dos resultados simulados e experimentais.

Figura 58 - Esquema do sistema SHM proposto para o caso do problema

de corrosão em estruturas laminares de alumínio.

Figura 59 - Energia por linha de deformação, associada cada um dos

88 padrões de corrosão simulados.

Figura 60 - Detecção da linha onde se encontra a corrosão por meio da comparação da energia com o limiar.

Figura 61 - Variação do erro de detecção com o tamanho da malha de sensores.

Figura 62 - Comparação entre as previsões das RNA e os valores de referência da largura das corrosões. Os dados apresentados à RNA nesse caso são distintos dos usados na fase de treinamento e validação. 103 Figura 63 - Comparação entre as previsões das RNA e os valores de referência de comprimento das corrosões. Os dados apresentados à RNA nesse caso são distintos dos usados na fase de treinamento e validação.103 Figura 64 - Comparação entre as previsões das RNA e os valores de referência da profundidade das corrosões. Os dados apresentados à RNA nesse caso são distintos dos usados na fase de treinamento e validação. 104 Figura 65 - Ilustração de uma curva típica de PoD. 105 Figura 66 - Dados de classificação quanto ao defeito. 107 Figura 67 - Ilustração de uma curva típica de PoD. 107 Figura 68 - Dados utilizados para a construção da curva de PoD. 108 Figura 69 - Ilustração de uma curva típica de PoD. 109 Figura 70 - Desenho esquemático, representando a disposição da camada extra no interior do compósito, a qual tem o papel 
de simular a delaminação.

Figura 71 - Corpo de prova instrumentado com os atuadores piezelétricos. 112 Figura 72 - Visão das camadas do compósito. No esquema da esquerda a delaminação está modelada entre as camadas 8 e 9 enquanto no esquema da direita a delaminação esta entre as camadas 4 e 5.

Figura 73 - Desenho esquemático da placa de compósito, com uma delaminação quadrada de lados com 25,4mm, instrumentada com uma malha de sensores fictícios espalhados sobre a sua superfície.

Figura 74 - Deformação superficial por varredura de frequência $(10 \mathrm{kHz}$ a $24 \mathrm{kHz})$.

Figura 75 - Deformação superficial por varredura de frequência $(24 \mathrm{kHz}$ a $50 \mathrm{kHz})$.

Figura 76 - Deformação superficial por varredura de frequência com passo de $100 \mathrm{~Hz}(11 \mathrm{kHz}$ à $15 \mathrm{kHz})$.

Figura 77 - Padrões de deformação para diferentes Cpm submetidos a frequência de $11,2 \mathrm{kHz}$.

Figura 78 - Padrões de deformação para diferentes Cpm submetidos a frequência de $13,3 \mathrm{kHz}$.

Figura 79 - Padrões de deformação para diferentes Cpm submetidos a frequência de $13,5 \mathrm{kHz}$.

Figura 80 - Padrões de deformação para diferentes Cpm submetidos a frequência de $14,7 \mathrm{kHz}$.

Figura 81 - Mapa de Deformação (Situação 01, frequência de 11,3 kHz).

Figura 82 - Mapa de Deformação (Situação 2, frequência de 13,3kHz).

Figura 84 - Mapa de Deformação (Situação 4, frequência de 11,3kHz). 125

Figura 85 - Mapa de Deformação (Situação 5, frequência de 12,3kHz). 125

Figura 86 - Mapa de Deformação (Situação 6, frequência de 11,1kHz). 126

Figura 87 - Mapa de Deformação (Situação 7, frequência de 11,3kHz). 126

Figura 88 - Mapa de Deformação (Situação 8, frequência de 11,3kHz). 127

Figura 89 - Mapa de Deformação (Situação 9, frequência de 13,8kHz). 127

Figura 90 - Mapa de Deformação (Situação 10, frequência de 11,3kHz). 128

Figura 91 - Mapa de Deformação (Situação 11, frequência de 11,3kHz). 128 
Figura 92 - Mapa de Deformação (Situação 12, frequência de 11,kHz).

Figura 93 - Mapa de Deformação da superfície superior e inferior com uma frequência de excitação de $11,3 \mathrm{kHz}$.

Figura 94 -- Mapa de Deformação da superfície superior e inferior com uma frequência de excitação de $13,3 \mathrm{kHz}$.

Figura 95 - Mapa de Deformação da superfície superior e inferior com uma frequência de excitação de $13,8 \mathrm{kHz}$.

Figura 96 - Mapas de Deformação em diferentes camadas e frequência de excitação de 13,3kHz (Delaminação de 1 Polegada quadrada). 132 Figura 97 - Mapa de Deformação em diferentes camadas e frequência de excitação de 13,4kHz (Delaminação de 1 Polegada quadrada). 132 Figura 98 - Mapa de Deformação em diferentes camadas e frequência de excitação de 13,5kHz (Delaminação de 1 Polegada quadrada). 133 Figura 99 - Mapa de Deformação em diferentes camadas e frequência de excitação de 13,3kHz (Delaminação de 1,5 Polegada quadrada). 133 Figura 100 - Mapa de Deformação em diferentes camadas e frequência de excitação de 13,4kHz (Delaminação de 1,5 Polegada quadrada). 134 Figura 101 - Mapa de Deformação em diferentes camadas e frequência de excitação de 13,5kHz (Delaminação de 1,5 Polegada quadrada). 134 Figura 102 - Mapa de Deformação em diferentes camadas e frequência de excitação de 13,3kHz (Delaminação de 2 Polegada quadrada). 135 Figura 103 - Mapa de Deformação em diferentes camadas e frequência de excitação de 13,4kHz (Delaminação de 2 Polegada quadrada). 135 Figura 104 - Mapa de Deformação em diferentes camadas e frequência de excitação d3e 13,5kHz (Delaminação de 2 Polegada quadrada). 136 Figura 105 - Grade de Sensores espalhados de $15 \mathrm{~mm}$ em $15 \mathrm{~mm}$.

Figura 106 - Mapa de deformação de $1 \mathrm{~mm}$ em $1 \mathrm{~mm}$ e com defeito de $6,35 \mathrm{~mm}$ por $6,35 \mathrm{~mm}$.

Figura 107 - Mapa de deformação de $1 \mathrm{~mm}$ em $1 \mathrm{~mm}$ e com defeito de $25,4 \mathrm{~mm}$ por $25,4 \mathrm{~mm}$. Figura 108 - Mapa de deformação de 1mm em 1mm e com defeito de $50,8 \mathrm{~mm}$ por $50,8 \mathrm{~mm}$.

Figura 109 - Mapa de deformação de $1 \mathrm{~mm}$ em $1 \mathrm{~mm}$ e com 
defeito de $25,4 \mathrm{~mm}$ por $12,7 \mathrm{~mm}$.

Figura 110 - Mapa de deformação de $1 \mathrm{~mm}$ em $1 \mathrm{~mm}$ e com defeito de $25,4 \mathrm{~mm}$ por $50,8 \mathrm{~mm}$.

Figura 111 - Mapa de deformação de $1 \mathrm{~mm}$ em $1 \mathrm{~mm}$ e com defeito de $12,7 \mathrm{~mm}$ por $63,1 \mathrm{~mm}$.

Figura 112 - Grade de Sensores espalhados de 30mm em 30mm.

Figura 113 - Mapa de deformação de $1 \mathrm{~mm}$ em $1 \mathrm{~mm}$ e com defeito de $6,35 \mathrm{~mm}$ por $6,35 \mathrm{~mm}$.

Figura 114 - Mapa de deformação de $1 \mathrm{~mm}$ em 1mm e com defeito de $25,4 \mathrm{~mm}$ por $25,4 \mathrm{~mm}$.

Figura 115 - Mapa de deformação de $1 \mathrm{~mm}$ em $1 \mathrm{~mm}$ e com defeito de $50,8 \mathrm{~mm}$ por $50,8 \mathrm{~mm}$.

Figura 116 - Mapa de deformação de $1 \mathrm{~mm}$ em $1 \mathrm{~mm}$ e com defeito de $25,4 \mathrm{~mm}$ por $12,7 \mathrm{~mm}$.

Figura 117 - Mapa de deformação de $1 \mathrm{~mm}$ em $1 \mathrm{~mm}$ e com defeito de $25,4 \mathrm{~mm}$ por $50,8 \mathrm{~mm}$.

Figura 118 - Mapa de deformação de $1 \mathrm{~mm}$ em $1 \mathrm{~mm}$ e com defeito de $12,7 \mathrm{~mm}$ por $63,1 \mathrm{~mm}$.

Figura 119 - Grade de Sensores espalhados de 50mm em 50mm.

Figura 120 - Mapa de deformação de $1 \mathrm{~mm}$ em $1 \mathrm{~mm}$ e com defeito de $6,35 \mathrm{~mm}$ por $6,35 \mathrm{~mm}$.

Figura 121 - Mapa de deformação de $1 \mathrm{~mm}$ em $1 \mathrm{~mm}$ e com defeito de $25,4 \mathrm{~mm}$ por $25,4 \mathrm{~mm}$.

Figura 122- Mapa de deformação de $1 \mathrm{~mm}$ em $1 \mathrm{~mm}$ e com defeito de $50,8 \mathrm{~mm}$ por $50,8 \mathrm{~mm}$.

Figura 123 - Mapa de deformação de $1 \mathrm{~mm}$ em $1 \mathrm{~mm}$ e com defeito de $25,4 \mathrm{~mm}$ por $12,7 \mathrm{~mm}$.

Figura 124 - Mapa de deformação de $1 \mathrm{~mm}$ em $1 \mathrm{~mm}$ e com defeito de $25,4 \mathrm{~mm}$ por $50,8 \mathrm{~mm}$.

Figura 125 - Mapa de deformação de $1 \mathrm{~mm}$ em $1 \mathrm{~mm}$ e com defeito de $12,7 \mathrm{~mm}$ por $63,1 \mathrm{~mm}$.

Figura 126 - Foto do Coupon suspenso por fios no laboratório 
Figura 127 - Sinal obtido pela convolução do espectro do laser e da FBG.

Figura 128 - Desenho esquemático do sistema de medição do Coupon.

Figura 129 - Representação da configuração da grade de 20 sensores FBG.

Figura 130 - Mapa de deformação obtidos experimentalmente,

com uma excitação à $13,3 \mathrm{kHz}$.

Figura 131 - Mapa de deformação obtidos experimentalmente,

com uma excitação à $13,4 \mathrm{kHz}$.

Figura 132 - Mapa de deformação obtidos experimentalmente, com uma excitação à $13, \mathrm{kHz}$.

Figura 133 - Mapas de deformação por frequências de excitação.

Figura 134 - Esquemático geral de detecção.

Figura 135 - Esquemático do algoritmo desenvolvido

para a detecção de delaminação em uma placa de material compósito.

Figura 136 - Mapas de probabilidade de se obter um caso de

$$
\text { defeito (delaminação). }
$$

Figura 137- Delaminação de dimensões iguais à 0,5 polegadas por 0,5 polegadas.

Figura 138 - Delaminação de dimensões iguais à 0,5 polegadas

por 1,5 polegadas.

Figura 139- Delaminação de dimensões iguais à 0,5 polegadas

por 2,5 polegadas.

Figura 140 - Delaminação de dimensões iguais à 0,25 polegadas

por 0,25 polegadas.

Figura 141 - Delaminação de dimensões iguais à 0,75 polegadas por 0,75 polegadas.

Figura 142 - Delaminação de dimensões iguais à 1,0 polegadas

por 1,0 polegadas.

Figura 143 - Delaminação de dimensões iguais à 1,0 polegadas

por 0,5 polegadas.

Figura 144 - Delaminação de dimensões iguais à 1,0 polegadas por 2,0 polegadas.

Figura 145 - Delaminação de dimensões iguais à 1,5 polegadas por 1,0 polegadas. 
Figura 146 - Delaminação de dimensões iguais à 1,5 polegadas por 1,5 polegadas.

Figura 147 - Delaminação de dimensões iguais à 2,0 polegadas por 0,5 polegadas.

Figura 148 - Delaminação de dimensões iguais à 2,0 polegadas

por 2,0 polegadas. 160

Figura 149 - Dados classificados por defeito (Delaminação). 163

Figura 150 - Curva de PoD obtida com os dados simulados para os coupons. 163

Figura 151 - Resultados experimentais e simulados contra a incerteza de medição. 


\section{Lista de Tabelas}

Tabela 1 - Características da placa modelada numericamente. 80

$\begin{array}{ll}\text { Tabela } 2 \text { - Modelos de carregamento realizados. } & 81\end{array}$

Tabela 3 - Área das corrosões introduzidas no modelo numérico. 82

Tabela 4 - Resultado das incertezas para o primeiro ensaio de tração. 94

Tabela 5 - Resultado das incertezas para o segundo ensaio de tração. 95

Tabela 6 - Erros registrados no ensaio da placa de alumínio. 97

Tabela 7 - Erro médio quadrático dos resultados obtidos pelas RNAs. 104

Tabela 8 - Respostas do sistema MSE aos dados experimentais. 104

Tabela 9 - Posicionamento de cada atuador com relação ao seu centro. 111

Tabela 10 - Tamanhos das delaminações testadas nas simulações. 113

Tabela 11 - Dimensões das delaminações testadas com respeito à detecção. 157

Tabela 12 - Relação das delaminações testadas e suas detecções. 160

Tabela 13 - Resultados de classificação das delaminações nos testes simulados 162

Tabela 14 - Posicionamento da delaminação pelo sistema de detecção. 166

Tabela 15 - PoD obtidas para os modelos estático e dinâmico. 167 
Só existem dois dias no ano que nada pode ser feito. Um se chama ontem e o outro se chama amanhã, portanto hoje é o dia certo para amar, acreditar, fazer e principalmente viver. 